\title{
Poor Motor Coordination Elicits Altered Lower Limb Biomechanics in Young Football (Soccer) Players: Implications for Injury Prevention through Wearable Sensors
}

\author{
Stefano Di Paolo ${ }^{1}\left({ }\right.$, Stefano Zaffagnini $^{2,3, *}{ }^{-}$, Nicola Pizza $^{3}$, Alberto Grassi ${ }^{3}$ and Laura Bragonzoni ${ }^{1}$ \\ 1 Department for Life Quality Studies, University of Bologna, 40136 Bologna, Italy; \\ stefano.dipaolo@ior.it (S.D.P.); laura.bragonzoni4@unibo.it (L.B.) \\ 2 Department of Biomedical and Neuromotor Sciences, University of Bologna, 40136 Bologna, Italy \\ 3 Orthopaedic and Traumatologic Clinic II, IRCCS Istituto Ortopedico Rizzoli, 40136 Bologna, Italy; \\ nicola.pizza@ior.it (N.P.); alberto.grassi@ior.it (A.G.) \\ * Correspondence: stefano.zaffagnini@unibo.it; Tel.: +39-051-6366507
}

\section{check for} updates

Citation: Di Paolo, S.; Zaffagnini, S.; Pizza, N.; Grassi, A.; Bragonzoni, L. Poor Motor Coordination Elicits Altered Lower Limb Biomechanics in Young Football (Soccer) Players: Implications for Injury Prevention through Wearable Sensors. Sensors 2021, 21, 4371. https://doi.org/ $10.3390 / \mathrm{s} 21134371$

Academic Editors: Alberto Greco and Alejandro Callara

Received: 17 May 2021

Accepted: 24 June 2021

Published: 25 June 2021

Publisher's Note: MDPI stays neutral with regard to jurisdictional claims in published maps and institutional affiliations.

Copyright: (c) 2021 by the authors. Licensee MDPI, Basel, Switzerland. This article is an open access article distributed under the terms and conditions of the Creative Commons Attribution (CC BY) license (https:// creativecommons.org/licenses/by/ $4.0 /)$.

\begin{abstract}
Motor coordination and lower limb biomechanics are crucial aspects of anterior cruciate ligament (ACL) injury prevention strategies in football. These two aspects have never been assessed together in real scenarios in the young population. The present study aimed to investigate the influence of motor coordination on lower limb biomechanics in young footballers during an on-thepitch training. Eighteen juvenile football players $(10 \mathrm{y} \pm 2 \mathrm{~m})$ were enrolled. Each player performed a training drill with sport-specific movements (vertical jump, agility ladders, change of direction) and the Harre circuit test (HCT) to evaluate players' motor coordination. Wearable inertial sensors (MTw Awinda, Xsens) were used to assess lower limb joint angles and accelerations. Based on the results of the HCT, players were divided into poorly coordinated (PC) and well-coordinated (WC) on the basis of the literature benchmark. The PC group showed a stiffer hip biomechanics strategy (up to $40 \%$ lower flexion angle, ES = 2.0) and higher internal-external hip rotation and knee valgus $(p<0.05)$. Significant biomechanical limb asymmetries were found only in the PC group for the knee joint (31-39\% difference between dominant and non-dominant limb, ES 1.6-2.3). Poor motor coordination elicited altered hip and knee biomechanics during sport-specific dynamic movements. The monitoring of motor coordination and on-field biomechanics might enhance the targeted trainings for ACL injury prevention.
\end{abstract}

Keywords: wearable sensors; joint kinematics; football; motor coordination; injury prevention; ACL

\section{Introduction}

Motor coordination plays a crucial role in injury prevention strategies in football (soccer) at all levels. Such an ability is acquired in the prepubertal period, which is also when children usually approach football, and entails dexterity, neuromotor control, and flexibility. Recent studies [1,2] underlined the importance of training the different aspects of motor coordination already in the youth to reduce the risk of non-contact musculoskeletal injuries, by acting on both intrinsic and extrinsic risk factors. Alongside motor coordination, players' biomechanics has gained considerable interest in preventative training programs [3-5]. Despite their comprehensiveness and quality, these programs did not successfully reduce injury rates in the young population as they did in elite adult players [6-9], and the incidence of severe injuries (e.g., anterior cruciate ligament, ACL injury) has doubled in the pediatric football players' population in the last 10 years [10]. Hence, innovative prevention strategies might require a deeper comprehension of players' biomechanics and motor control interaction.

On-field biomechanical analyses of complex movements through wearable inertial sensor systems are gaining growing interest [11-13]. Compared with the in-lab standard 
assessments, the use of wearables in real scenarios (e.g., sport-specific pitch) extends the opportunities to monitoring players' motion and offering real-time feedback. These aspects have particular importance for team sports, where the interaction with the environment (teammates, opponents, etc.) is predominant. Nonetheless, on-field multi-joint biomechanics of young football players were investigated in only one study and never in relation to motor coordination. Such an analysis could highlight biomechanical alterations due to poor motor control in the light of injury prevention.

Therefore, the present study aimed to investigate the influence of motor coordination on lower limb biomechanics through wearable inertial sensors in young football players during a typical on-the-pitch training. The hypotheses were that (I) players deemed as having poor motor coordination (dexterity) would elicit altered lower limb biomechanics during football-specific tasks and that (II) these biomechanical alterations would be associated to the risk factors targeted in ACL injury prevention strategies.

\section{Materials and Methods}

\subsection{Participants}

Eighteen juvenile football players (one team) were enrolled in the study. Players were all male, aged $10.4 \pm 0.4$ years (range 10-11), BMI $18.7 \pm 3.8$, and had no history of previous musculoskeletal injury. Each player's parent/tutor signed informed consent and agreed to their own child's performance data acquisition and treatment for research purposes. The team coach was present and supervised all the data acquisition phases. This study obtained approval from the Bioethical Committee of the University of Bologna (ID: 25861 10 February 2020).

\subsection{Data Collection}

The data collection was performed on the team's football pitch, equipped with artificial turf. The data were collected in a single day during a standard training at the middle of the regular football season. Every player was asked to perform two different motor activities: (I) the Harre circuit test to evaluate the coordinative motor ability [14], and (II) a training drill with football-specific movements. The former was used to inspect players' motor coordination, while the latter was used to inspect players' biomechanics.

The Harre circuit (I) is claimed as one of the most appropriate tests to evaluate prepubertal players' ability to coordinate complex dynamic movements [15-17]. The players were instructed to complete the circuit described by Chiodera et al. [15] (Appendix A) at the maximum speed. In short, the circuit requires the execution of a forward roll and three consecutive passages above and underneath three obstacles [15].

The football-specific training drill (II) consisted of three tasks (Figure 1): a maximal vertical jump (MVJ); a low skip in the agility ladder drills (ALD); and two changes of direction (COD) at $90^{\circ}$ of $5 \mathrm{~m}$ each, one right and one left. Such tasks resemble typical movements of football training and matches and have an intrinsic relation with motor coordination: an efficient MVJ requires both muscle explosiveness, intersegmental coordination, and balance during both the push-off phase and the landing phase [18-20]; the ALD requires intense and coordinated footwork [21,22]; a $90^{\circ} \mathrm{COD}$ requires multidirectional acceleration/deceleration phases, and are the basis of the agility tests $[23,24]$. The players were asked to perform their best and complete the training drill in the lowest time possible. They received only a few indications on how to perform each task to let them move naturally.

Each player performed three unrecorded trials before the real acquisition to become confident with the two activities. The two activities were performed consecutively after a short warm-up. 


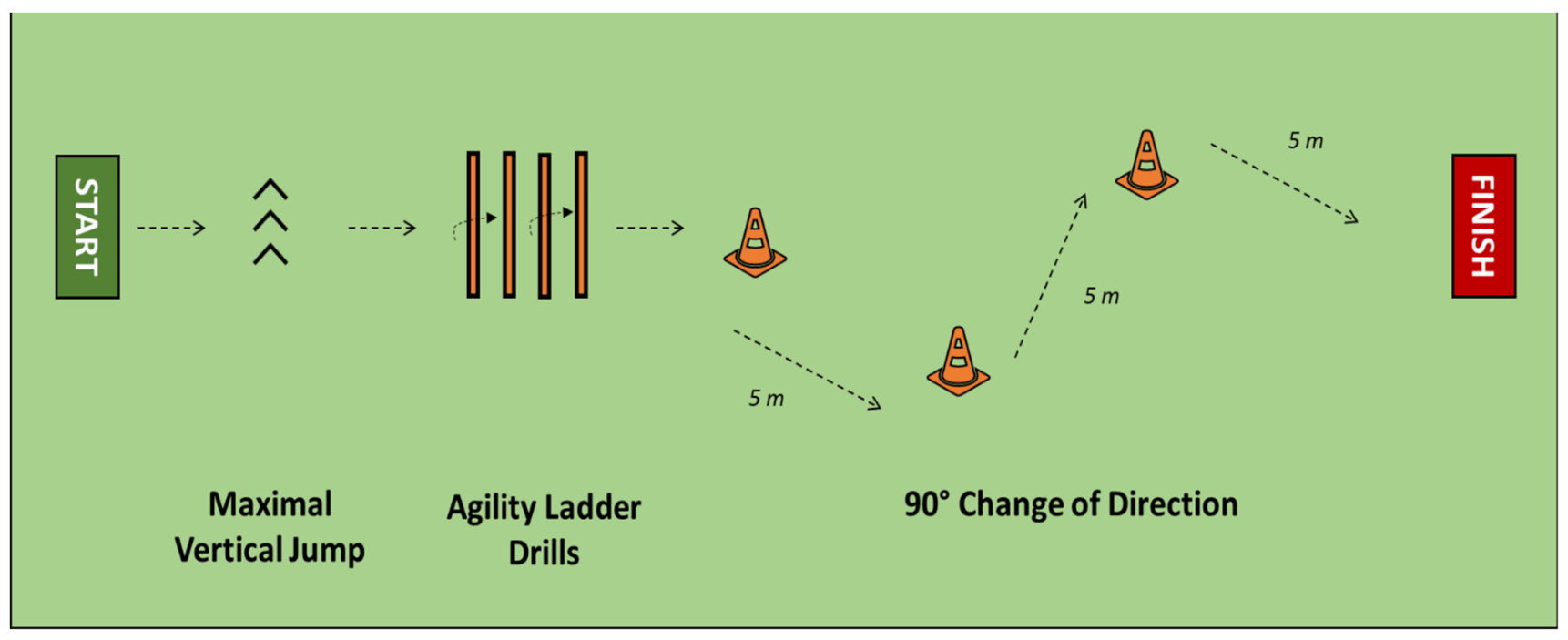

Figure 1. Representation of the football-specific training drill used for the biomechanical assessment. The players were asked to perform the drill at the maximum speed possible. Biomechanical data were recorded through a wearable inertial sensor system.

Motion data were collected during the football-specific training drill through a set of seven wearable inertial sensors (Xsens MVN, Xsens Technologies, Enschede, The Netherlands) placed bilaterally on the feet, shins, thighs, and lumbar L5 (Figure 2). The sensors (integrated triaxial accelerometers, gyroscopes, and magnetometer) were secured to the body segments through Velcro straps either on the body or on the clothes. A single experienced operator carried out sensor placement for all the players. A static and dynamic system calibration was conducted per single player before the data collection. The accuracy of the wearable sensor system in the kinematical assessment of high-dynamics movements was previously inspected against the gold standard optoelectronic marker-based motion capture [13]: the normalized root mean square error was found to range between $8 \%$ and $14 \%$ for the sagittal plane joint angles (excellent inter-system correlation) and between $20 \%$ and $43 \%$ for the frontal and transverse plane joint angles (fair-to-excellent inter-system correlation) in lower limbs and trunk.

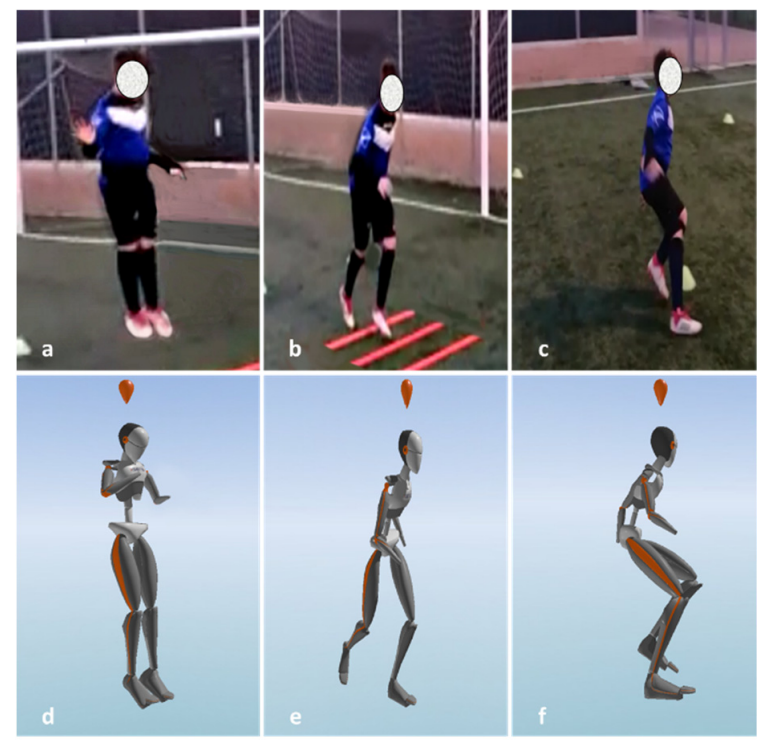

Figure 2. Example of a football player performing the football-specific training drill with the real-time kinematical output from wearables: $(\mathbf{a}, \mathbf{b})$ the maximal vertical jump; $(\mathbf{c}, \mathbf{d})$ the agility ladder drills; $(\mathbf{e}, \mathbf{f})$ the two $90^{\circ}$ changes of direction. 


\subsection{Data Analysis}

The time elapsed for the Harre circuit test was recorded through a digital soccer watch [15] by a single operator for all the players to the nearest $0.01 \mathrm{~s}$. A benchmark value of $15.7 \pm 2.8 \mathrm{~s}$ was considered for completing the Harre circuit based on a previous cohort study on 241 healthy children aged 8-10 years [17]. The choice of a literature-based benchmark to inspect players' coordination was done for the sake of study reproducibility. According to the benchmark value, the players were divided into two groups: the players with time elapsed lower or within the benchmark value \pm SD (i.e., $<18.5 \mathrm{~s}$ ) were classified as well coordinated (WC group), while the players with time elapsed higher than the benchmark value \pm SD (i.e., $>18.5$ s) were classified as poorly coordinated (PC group) [25]. In this way, the sub-group of players performing worse than the literature benchmark was split from those performing on average or even better.

Hip, knee, and ankle biomechanics (joint angles and joint accelerations) were recorded for all the tasks of the training drill at a sampling frequency of $100 \mathrm{~Hz}$ and $\mathrm{HD}$ re-processed for drift inaccuracies reduction. The joint angles on frontal (abduction-adduction, AA for hip and ankle; varus-valgus, VV for the knee), transverse (internal-external rotation, IE), and sagittal (flexion-extension, FE) plane were evaluated in terms of ranges and peak values; the joint accelerations on anteroposterior (AP), mediolateral (ML) and vertical (V) axes were evaluated in terms of ranges, positive peaks $(+)$, and negative peaks $(-)$.

The biomechanical data were evaluated in terms of dominant and non-dominant limbs, respectively defined as the kicking and the standing limb. Furthermore, the limb asymmetry within groups (i.e., the percentage difference between the dominant and non-dominant limb) was computed for each biomechanical variable. Data analysis was performed in a customized Matlab script (The MathWorks, Natick, MA, USA).

\subsection{Statistical Analysis}

The Shapiro-Wilk test was used to verify the normal distribution of the data. Normaldistributed continuous variables were presented as mean and standard deviation (SD), while categorical variables were presented as percentages over the total. The two-way ANOVA was used to assess the statistical differences between the players with coordination (WC and PC groups) and limb asymmetry (dominant and non-dominant limb) as factors. The differences between the single groups were assessed through the two-tailed Student's $\mathrm{t}$-test with Bonferroni correction for multiple comparisons. The differences were considered statistically significant for $p<0.05$. Cohen's d effect size (ES [26]) was calculated alongside $p$-value: ES of $0.2,0.5,0.8,1.4$, and 2.0 were considered small, medium, large, very large, and huge, respectively [27]. Only statistically significant differences with ES $\geq 1.5$ (very large-huge) were reported in the Results section and further discussed to limit the type II error. All the analyses were performed in Matlab.

\section{Results}

\subsection{Harre Circuit Test (Coordination)}

The WC group players $(\mathrm{n}=10)$ took $16.4 \pm 0.9 \mathrm{~s}$ to complete the Harre circuit, while the PC group players $(\mathrm{n}=8)$ took $20.5 \pm 2.9 \mathrm{~s}(p=0.009)$. Demographics (BMI, age, weight, height) were not statistically different between the two groups $(p>0.05)$.

\subsection{Training Drill (Biomechanics)}

A higher peak flexion angle was found in the WC group compared with the PC group for hip joint in dominant and non-dominant limb both in MVJ and ALD tasks (Table 1, Appendix B). In the MVJ task, the WC group showed a higher peak varus angle and a greater range of vertical ankle acceleration than the PC group. In the COD task, the PC group showed a wider range of internal-external hip rotation.

The presence of biomechanical limb asymmetry was found for the PC group players in the COD task in terms of knee varus-valgus range and positive peak and range of vertical knee acceleration (higher values for the dominant limb, Table 2). No limb asymmetries were found in the WC group. 
Table 1. Biomechanics through wearable sensors assessed according to motor coordination.

\begin{tabular}{lccccc}
\hline & PC Group & WC Group & Diff $\%$ & Effect Size & $p$-Value \\
\hline Joint angles $\left(^{\circ}\right)$ & & & & & \\
Maximal Vertical Jump & & & & & \\
Hip flexion peak, dominant & $44.1 \pm 7.7$ & $59.8 \pm 12.8$ & $-36 \%$ & 1.5 & 0.019 \\
Hip flexion peak, non-dominant & $42.8 \pm 7.9$ & $61.2 \pm 10.6$ & $-43 \%$ & 2.0 & 0.004 \\
Knee varus peak, non-dominant & $-4.8 \pm 2.4$ & $-10.3 \pm 2.8$ & $-116 \%$ & 2.1 & 0.008 \\
Agility Ladder Drills & & & & & \\
Hip flexion peak, dominant & $50.4 \pm 7.3$ & $64.0 \pm 7.8$ & $-27 \%$ & 1.8 & 0.006 \\
Hip flexion peak, non-dominant & $48.8 \pm 8.3$ & $60.2 \pm 6.9$ & $-23 \%$ & 1.5 & 0.017 \\
Change of direction & $28.0 \pm 4.6$ & $21.5 \pm 4.3$ & $+23 \%$ & 1.5 & 0.019 \\
Hip IE range, dominant & & & & & \\
Joint accelerations (m/s $\left.{ }^{2}\right)$ & & & & \\
Maximal Vertical Jump & & & & \\
Ankle V range, non-dominant & $163.6 \pm 31.8$ & $232.3 \pm 51.9$ & $-42 \%$ & 1.6 & 0.014 \\
\hline
\end{tabular}

Note: Only the significant differences $(p<0.05)$ with at least huge effect size $(\mathrm{ES} \geq 1.5)$ were reported; positive values of diff \% mean a higher magnitude for biomechanical variables of PC group; dominant limb means the preferred for kicking. Abbreviations: PC, poorly-coordinated players; WC, well-coordinated players; IE, internal-external; $\mathrm{V}$, vertical.

Table 2. Biomechanics asymmetries between dominant and non-dominant limb.

\begin{tabular}{|c|c|c|c|c|c|}
\hline & Dominant & Non-Dominant & Diff \% & Effect Size & $p$-Value \\
\hline \multicolumn{6}{|l|}{ Joint angles $\left({ }^{\circ}\right)$} \\
\hline \multicolumn{6}{|l|}{ Change of direction } \\
\hline Knee VV range, PC Group & $23.2 \pm 6.7$ & $14.5 \pm 3.5$ & $+38 \%$ & 1.6 & 0.013 \\
\hline \multicolumn{6}{|l|}{ Joint accelerations $\left(\mathrm{m} / \mathrm{s}^{2}\right)$} \\
\hline \multicolumn{6}{|l|}{ Change of direction } \\
\hline Knee V peak (+), PC Group & $119.9 \pm 19.8$ & $72.7 \pm 20.5$ & $+39 \%$ & 2.3 & 0.001 \\
\hline Knee $\mathrm{V}$ range, $\mathrm{PC}$ Group & $183.9 \pm 36$ & $126.6 \pm 37.4$ & $+31 \%$ & 1.6 & 0.013 \\
\hline
\end{tabular}

Note: Only the significant differences $(p<0.05)$ with at least huge effect size (ES $\geq 1.5)$ were reported; positive values of diff \% mean a higher magnitude for kinematic variables of the dominant limb; dominant limb means the preferred for kicking. Abbreviations: PC, poorly-coordinated players; VV, varus-valgus; V, vertical.

\section{Discussion}

The present study is the first aiming to investigate how motor coordination influences the lower limb biomechanics during on-the-pitch training through wearable inertial sensors in young football players. The most important finding was that biomechanical differences were found between well-coordinated (average and good results in the Harre circuit test [17]) and poorly-coordinated (higher time elapsed in the Harre circuit test [17]) players in all the investigated tasks. In particular, poorly-coordinated players seem more prone to adopt "dangerous" biomechanical strategies in light of non-contact injuries, such as ACL injury [28], thus confirming the hypotheses.

The present study tackles several trend topics in orthopedics, sports medicine, and human movement analysis: the influence of motor coordination on biomechanics towards movement quality and injury prevention; the investigation in a sport-specific real scenario; the focus on a juvenile population, namely one younger than that with the highest odds of non-contact injury and the most severe implications for health and career $[3,10,29,30]$. The use of wearable sensors for multiple joint biomechanics data collection and processing represents a further significant technological advancement for this type of analysis.

The results suggest that motor coordination influences players' hip biomechanics. Poorly coordinated players exhibited up to $43 \%$ lower hip flexion peak angle than the wellcoordinated players in both the MVJ and the ALD tasks regardless of limb dominance. The only previous on-filed multi-joint biomechanical investigation on young football players (11-12 years) through wearable sensors also highlighted differences in hip biomechanics in the drop jump test after a fatigue protocol [31]. A stiff hip biomechanical strategy has been associated with poor core balance and increased intra-articular knee and ankle mechanical loads [32-35]. The achievement of the sagittal plane range of motion in landings, highspeed movements, and cut maneuvers is a critical target in preventative programs to reduce the risk for lower limb non-contact injury [36,37]. A prospective analysis on 90 adolescent 
female athletes recently demonstrated a higher relative risk for ACL injury in the presence of limited hip flexion angle [5].

Motor coordination was also associated with frontal and transverse plane biomechanics in the ALD and the COD tasks. The PC group showed higher hip transverse plane rotations, while the WC group showed higher varus peak angles. Both aspects are meaningful to preventative training: e.g., in ACL injury prevention, the main target is the limitation of the external knee moments caused by the coupling of hip internal rotation, hip adduction, and knee valgus [38-43]. Hewett et al. [44,45] and Raisanen et al. [46] demonstrated a reduction of injury risk after targeted neuromuscular training focused on frontal plane control in adolescent athletes following ACL-reconstruction. From this perspective, poorly-coordinated players seem to exhibit a more dangerous pattern, while well-coordinated players seem to exhibit a more protective strategy. Since the training drill was performed at the maximum speed possible, i.e., with a performance-driven outcome, it is possible that such patterns also occur during regular training and matches.

Statistically significant differences between dominant and non-dominant limb biomechanics (limb asymmetry) were found only in the poorly-coordinated players. More specifically, differences regarded the knee joint during the COD task, and greater varus-valgus angle and vertical accelerations were found for the dominant limb. This finding supports a connection between poor motor coordination and altered biomechanics: first, the COD is claimed as the most demanding sport-specific task in terms of motor coordination and biomechanics [47] and the most frequent situational pattern for non-contact injuries [28]; second, biomechanical asymmetries are often associated with the risk of muscular and ligamentous non-contact injury $[39,48]$, and are addressed as a pivotal aspect of pre- and rehabilitation; and, third, higher incidence of non-contact injury has been found for dominant limb in football [48-51]. The presence of limb asymmetries during dynamic movements in the young population might be indicative of sub-optimal neuromotor control development, leading to an increased risk of future injury.

The present study highlighted that poor motor coordination reflects altered biomechanical patterns in young football players. Such patterns are in line with the literature on non-contact ACL injury mechanism and prevention and should be further investigated to offer precious insights into the influence of poor motor coordination and football injuries. In particular, the incidence of dangerous patterns in players with limited coordination might be investigated in the presence of sport-specific external perturbations (e.g., ball, opponents) and after targeted multi-tasking training sessions.

The present study has several limitations. First, the analysis was conducted on a small number of players from a single male football team aged 10-11 years. Thus, the results cannot be conclusive nor generalizable to other sport-specific tasks. Despite the small sample size, the significant differences were all adequately powered ( $E S \geq 1.5$, power $\geq 80 \%$ ), thus reducing the risk for type II error. Second, the analysis was performed a single time. Further follow-up acquisitions would have given more robust insights regarding players' motion variability. Third, the division in well-coordinated and poorly-coordinated players was based on a single parameter (time elapsed in the Harre circuit test) [17]. Although a multiple-test battery could offer a more robust indication of players' motor coordination [2], the Harre circuit test is a trusted method to assess such an ability in preadolescent footballers [15,17], and has recently been modified to be extended to adolescent ones [52]. The choice of a literature-based benchmark for group split through the Harre circuit test was done to limit the bias related to the analysis of a single cohort of players (one team) in identifying those with poor coordination. Recent studies also proposed the use of joint coordination variability as a predictive measure for non-contact injury risk [53], thus offering a comprehensive investigation of the neuromotor and biomechanical aspects of the movement. Lastly, little knowledge on multi-joint on-field biomechanics is present in the literature, making it difficult to inspect the present study results. In particular, no onfield validation or data collection of football-specific movements is provided. Indeed, the present study represents one of the first attempts to assess football players' biomechanics 
on-field during regular training and highlights a possible use of wearable inertial sensors in pediatric injury prevention. Such technology could be a valuable support to coaches and sports physicians in identifying movement patterns and strengthening preventative strategies. The young and competitive population might benefit most from continuous monitoring of coordinative and biomechanical risk factors for ACL non-contact injury.

\section{Conclusions}

Poor motor coordination was associated with altered lower limb biomechanics in young football players during typical movements of training and matches. Biomechanical investigations in real scenarios through wearables with specific regards to motor coordination might enhance the targeted trainings for non-contact ACL injury prevention.

Author Contributions: All the authors actively contributed to the development of the present work. In particular: conceptualization, S.D.P., L.B. and S.Z.; methodology, S.D.P. and L.B.; software, S.D.P. and L.B.; formal analysis, S.D.P.; investigation, S.D.P. and L.B.; resources, S.Z. and L.B.; data curation, S.D.P. and N.P.; writing—original draft preparation, S.D.P. and N.P.; writing—review and editing, A.G. and S.Z.; visualization, S.D.P., N.P. and A.G.; supervision, S.Z.; project administration, L.B.; funding acquisition, L.B. and S.Z. All authors have read and agreed to the published version of the manuscript.

Funding: This research received no external funding.

Institutional Review Board Statement: The study was conducted according to the guidelines of the Declaration of Helsinki and approved by the Bioethical Committee of the University of Bologna (ID: 2586110 February 2020).

Informed Consent Statement: Informed consent was obtained from all parents/tutors of the subjects involved in the study. Written informed consent was obtained from the parent/tutor of the subject in Figure 2 to publish this paper.

Data Availability Statement: Data are available on reasonable request and due to restrictions, e.g., privacy or ethical.

Acknowledgments: The authors would like to thank the S.C. Folgore Mirandola football team and its coach for the opportunity to conduct the study on the team players and for the support in the data acquisition.

Conflicts of Interest: The authors declare no conflict of interest.

\section{Appendix A}

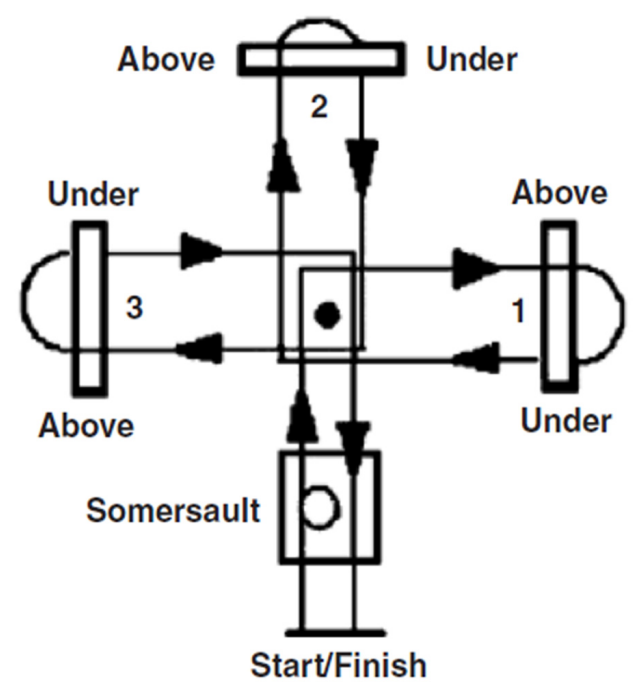

Figure A1. Harre circuit test for the assessment of players' motor coordination as reported by Chiodera et al. [15]. 


\section{Appendix B}

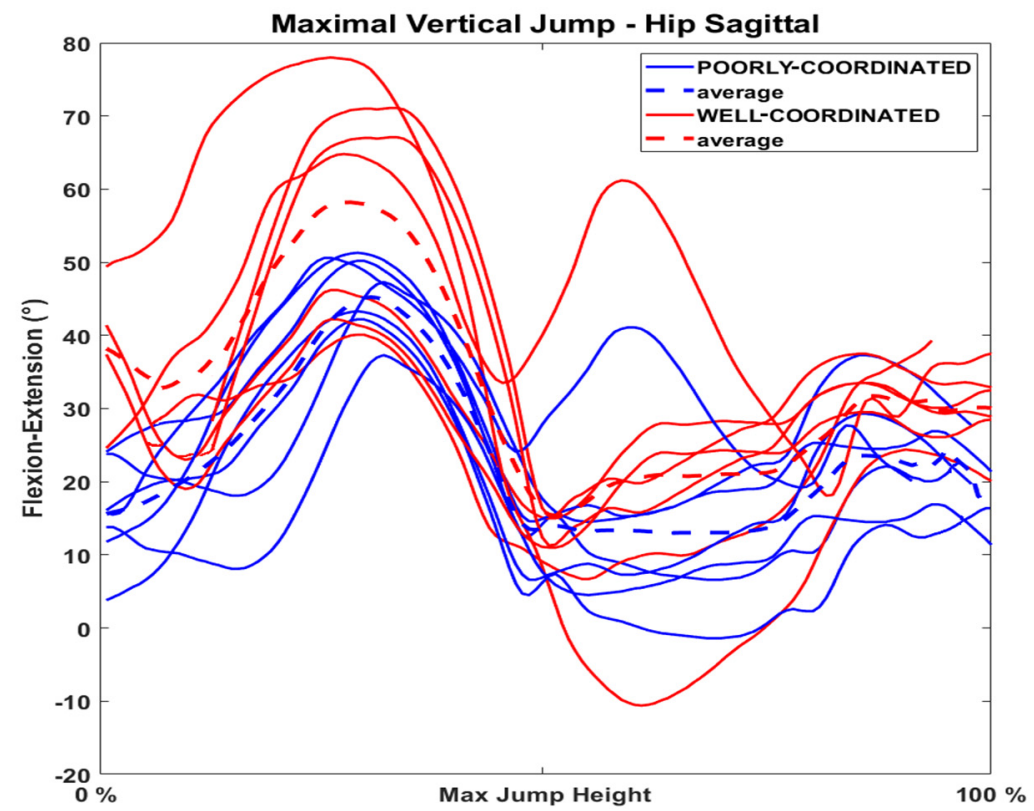

Figure A2. Example of waveform (dominant limb hip flexion-extension during the maximal vertical jump) extracted from the wearable sensors with distinction in poorly coordinated (blue) and wellcoordinated (red) players.

\section{References}

1. Watson, A.; Mjaanes, J.M.; Council on Sports Medicine and Fitness. Soccer Injuries in Children and Adolescents. Pediatrics 2019, 144. [CrossRef]

2. Dietvorst, M.; Brzoskowski, M.H.; van der Steen, M.; Delvaux, E.; Janssen, R.P.A.; Van Melick, N. Limited Evidence for Return to Sport Testing after ACL Reconstruction in Children and Adolescents under 16 Years: A Scoping Review. J. Exp. Orthop. 2020, 7, 83. [CrossRef] [PubMed]

3. Moksnes, H.; Engebretsen, L.; Seil, R. The ESSKA Paediatric Anterior Cruciate Ligament Monitoring Initiative. Knee Surg. Sports Traumatol. Arthrosc. 2016, 24, 680-687. [CrossRef]

4. Zebis, M.K.; Bencke, J.; Andersen, L.L.; Døssing, S.; Alkjaer, T.; Magnusson, S.P.; Kjaer, M.; Aagaard, P. The Effects of Neuromuscular Training on Knee Joint Motor Control during Sidecutting in Female Elite Soccer and Handball Players. Clin. J. Sport Med. Off. J. Can. Acad. Sport Med. 2008, 18, 329-337. [CrossRef]

5. Zebis, M.K.; Aagaard, P.; Andersen, L.L.; Hölmich, P.; Clausen, M.B.; Brandt, M.; Husted, R.S.; Lauridsen, H.B.; Curtis, D.J.; Bencke, J. First-Time Anterior Cruciate Ligament Injury in Adolescent Female Elite Athletes: A Prospective Cohort Study to Identify Modifiable Risk Factors. Knee Surg. Sports Traumatol. Arthrosc. 2021. [CrossRef] [PubMed]

6. Grooms, D.R.; Palmer, T.; Onate, J.A.; Myer, G.D.; Grindstaff, T. Soccer-Specific Warm-Up and Lower Extremity Injury Rates in Collegiate Male Soccer Players. J. Athl. Train. 2013, 48, 782-789. [CrossRef] [PubMed]

7. Slauterbeck, J.R.; Choquette, R.; Tourville, T.W.; Krug, M.; Mandelbaum, B.R.; Vacek, P.; Beynnon, B.D. Implementation of the FIFA 11+ Injury Prevention Program by High School Athletic Teams Did Not Reduce Lower Extremity Injuries: A Cluster Randomized Controlled Trial. Am. J. Sports Med. 2019, 47, 2844-2852. [CrossRef] [PubMed]

8. Soligard, T.; Nilstad, A.; Steffen, K.; Myklebust, G.; Holme, I.; Dvorak, J.; Bahr, R.; Andersen, T.E. Compliance with a Comprehensive Warm-up Programme to Prevent Injuries in Youth Football. Br. J. Sports Med. 2010, 44, 787-793. [CrossRef]

9. Steffen, K.; Emery, C.A.; Romiti, M.; Kang, J.; Bizzini, M.; Dvorak, J.; Finch, C.F.; Meeuwisse, W.H. High Adherence to a Neuromuscular Injury Prevention Programme (FIFA 11+) Improves Functional Balance and Reduces Injury Risk in Canadian Youth Female Football Players: A Cluster Randomised Trial. Br. J. Sports Med. 2013, 47, 794-802. [CrossRef]

10. Weitz, F.K.; Sillanpää, P.J.; Mattila, V.M. The Incidence of Paediatric ACL Injury Is Increasing in Finland. Knee Surg. Sports Traumatol. Arthrosc. 2020, 28, 363-368. [CrossRef]

11. van der Kruk, E.; Reijne, M.M. Accuracy of Human Motion Capture Systems for Sport Applications; State-of-the-Art Review. Eur. J. Sport Sci. 2018, 18, 806-819. [CrossRef] [PubMed]

12. Verheul, J.; Nedergaard, N.J.; Vanrenterghem, J.; Robinson, M.A. Measuring Biomechanical Loads in Team Sports-From Lab to Field. Sci. Med. Footb. 2020, 4, 246-252. [CrossRef] 
13. Di Paolo, S.; Lopomo, N.F.; Della Villa, F.; Paolini, G.; Figari, G.; Bragonzoni, L.; Grassi, A.; Zaffagnini, S. Rehabilitation and Return to Sport Assessment after Anterior Cruciate Ligament Injury: Quantifying Joint Kinematics during Complex High-Speed Tasks through Wearable Sensors. Sensors 2021, 21, 2331. [CrossRef]

14. Harre, D.; Barsch, J. Principles of Sports Training: Introduction to the Theory and Methods of Training; Sportverlag: Berlin, Gremany, 1982.

15. Chiodera, P.; Volta, E.; Gobbi, G.; Milioli, M.A.; Mirandola, P.; Bonetti, A.; Delsignore, R.; Bernasconi, S.; Anedda, A.; Vitale, M. Specifically Designed Physical Exercise Programs Improve Children's Motor Abilities. Scand. J. Med. Sci. Sports 2008, 18, 179-187. [CrossRef]

16. Trecroci, A.; Cavaggioni, L.; Caccia, R.; Alberti, G. Jump Rope Training: Balance and Motor Coordination in Preadolescent Soccer Players. J. Sports Sci. Med. 2015, 14, 792-798.

17. Dallolio, L.; Ceciliani, A.; Sanna, T.; Garulli, A.; Leoni, E. Proposal for an Enhanced Physical Education Program in the Primary School: Evaluation of Feasibility and Effectiveness in Improving Physical Skills and Fitness. J. Phys. Act. Health 2016, 13, 1025-1034. [CrossRef]

18. Wilczyński, B.; Hinca, J.; Ślęzak, D.; Zorena, K. The Relationship between Dynamic Balance and Jumping Tests among Adolescent Amateur Rugby Players. A Preliminary Study. Int. J. Environ. Res. Public Health 2021, 18, 312. [CrossRef] [PubMed]

19. Earp, J.E.; Joseph, M.; Kraemer, W.J.; Newton, R.U.; Comstock, B.A.; Fragala, M.S.; Dunn-Lewis, C.; Solomon-Hill, G.; Penwell, Z.R.; Powell, M.D.; et al. Lower-Body Muscle Structure and Its Role in Jump Performance during Squat, Countermovement, and Depth Drop Jumps. J. Strength Cond. Res. 2010, 24, 722-729. [CrossRef] [PubMed]

20. Dicesare, C.A.; Minai, A.A.; Riley, M.A.; Ford, K.R.; Hewett, T.E.; Myer, G.D. Distinct Coordination Strategies Associated with the Drop Vertical Jump Task. Med. Sci. Sports Exerc. 2020, 52, 1088-1098. [CrossRef] [PubMed]

21. Michailidis, Y.; Fatouros, I.G.; Primpa, E.; Michailidis, C.; Avloniti, A.; Chatzinikolaou, A.; Barbero-Álvarez, J.C.; Tsoukas, D.; Douroudos, I.I.; Draganidis, D.; et al. Plyometrics' Trainability in Preadolescent Soccer Athletes. J. Strength Cond. Res. 2013, 27, 38-49. [CrossRef]

22. Afonso, J.; da Costa, I.T.; Camões, M.; Silva, A.; Lima, R.F.; Milheiro, A.; Martins, A.; Laporta, L.; Nakamura, F.Y.; Clemente, F.M. The Effects of Agility Ladders on Performance: A Systematic Review. Int. J. Sports Med. 2020, 41, 720-728, Correction in 2020. [PubMed]

23. Altmann, S.; Ringhof, S.; Neumann, R.; Woll, A.; Rumpf, M.C. Validity and Reliability of Speed Tests Used in Soccer: A Systematic Review. PLoS ONE 2019, 14, e220982. [CrossRef]

24. Chiwaridzo, M.; Oorschot, S.; Dambi, J.M.; Ferguson, G.D.; Bonney, E.; Mudawarima, T.; Tadyanemhandu, C.; Smits-Engelsman, B.C.M. A Systematic Review Investigating Measurement Properties of Physiological Tests in Rugby. BMC Sports Sci. Med. Rehabil. 2017, 9, 24. [CrossRef] [PubMed]

25. Beekhuizen, K.S.; Davis, M.D.; Kolber, M.J.; Cheng, M.-S.S. Test-Retest Reliability and Minimal Detectable Change of the Hexagon Agility Test. J. Strength Cond. Res. 2009, 23, 2167-2171. [CrossRef]

26. Cohen, J. Statistical Power Analysis for the Behavioral Sciences, 2nd ed.; Lawrence Erlbaum Associates: Hillsdale, NJ, USA, 1988; ISBN 978-0-8058-0283-2.

27. Sawilowsky, S.S. New Effect Size Rules of Thumb. J. Mod. App. Stat. Meth. 2009, 8, 597-599. [CrossRef]

28. Della Villa, F.; Buckthorpe, M.; Grassi, A.; Nabiuzzi, A.; Tosarelli, F.; Zaffagnini, S.; Della Villa, S. Systematic Video Analysis of ACL Injuries in Professional Male Football (Soccer): Injury Mechanisms, Situational Patterns and Biomechanics Study on 134 Consecutive Cases. Br. J. Sports Med. 2020. [CrossRef]

29. Ardern, C.L.; Ekås, G.R.; Grindem, H.; Moksnes, H.; Anderson, A.; Chotel, F.; Cohen, M.; Forssblad, M.; Ganley, T.J.; Feller, J.A.; et al. Prevention, Diagnosis and Management of Paediatric ACL Injuries. Br. J. Sports Med. 2018, 52, 1297-1298. [CrossRef]

30. Silvers-Granelli, H.J.; Bizzini, M.; Arundale, A.; Mandelbaum, B.R.; Snyder-Mackler, L. Does the FIFA 11+ Injury Prevention Program Reduce the Incidence of ACL Injury in Male Soccer Players? Clin. Orthop. Relat. Res. 2017, 475, 2447-2455. [CrossRef]

31. Burboa, G.J.; Inostroza, M.M.; Bahamondes, F.M.; Lillo, U.P.; Hinzpeter, C.J. Comparison of the Angular Compartment of Hip Flexion Before and After Training in 11 to 12-Year-Old Soccer Players. JSEM 2019, 1, 4-10. [CrossRef]

32. Leppänen, M.; Pasanen, K.; Kujala, U.M.; Vasankari, T.; Kannus, P.; Äyrämö, S.; Krosshaug, T.; Bahr, R.; Avela, J.; Perttunen, J.; et al. Stiff Landings Are Associated With Increased ACL Injury Risk in Young Female Basketball and Floorball Players. Am. J. Sports Med. 2017, 45, 386-393. [CrossRef]

33. Kotsifaki, A.; Korakakis, V.; Whiteley, R.; Van Rossom, S.; Jonkers, I. Measuring Only Hop Distance during Single Leg Hop Testing Is Insufficient to Detect Deficits in Knee Function after ACL Reconstruction: A Systematic Review and Meta-Analysis. Br. J. Sports Med. 2020, 54, 139-153. [CrossRef]

34. Nguyen, A.-D.; Taylor, J.B.; Wimbish, T.G.; Keith, J.L.; Ford, K.R. Preferred Hip Strategy During Landing Reduces Knee Abduction Moment in Collegiate Female Soccer Players. J. Sport Rehabil. 2018, 27, 213-217. [CrossRef] [PubMed]

35. Pollard, C.D.; Sigward, S.M.; Powers, C.M. Limited Hip and Knee Flexion during Landing Is Associated with Increased Frontal Plane Knee Motion and Moments. Clin. Biomech. 2010, 25, 142-146. [CrossRef]

36. Ward, S.H.; Blackburn, J.T.; Padua, D.A.; Stanley, L.E.; Harkey, M.S.; Luc-Harkey, B.A.; Pietrosimone, B. Quadriceps Neuromuscular Function and Jump-Landing Sagittal-Plane Knee Biomechanics After Anterior Cruciate Ligament Reconstruction. J. Athl. Train. 2018, 53, 135-143. [CrossRef] 
37. King, E.; Richter, C.; Daniels, K.A.J.; Franklyn-Miller, A.; Falvey, E.; Myer, G.D.; Jackson, M.; Moran, R.; Strike, S. Biomechanical but Not Strength or Performance Measures Differentiate Male Athletes Who Experience ACL Reinjury on Return to Level 1 Sports. Am. J. Sports Med. 2021, 49, 918-927. [CrossRef]

38. Dempsey, A.R.; Lloyd, D.G.; Elliott, B.C.; Steele, J.R.; Munro, B.J. Changing Sidestep Cutting Technique Reduces Knee Valgus Loading. Am. J. Sports Med. 2009, 37, 2194-2200. [CrossRef] [PubMed]

39. Hewett, T.E.; Myer, G.D.; Ford, K.R.; Heidt, R.S.; Colosimo, A.J.; McLean, S.G.; van den Bogert, A.J.; Paterno, M.V.; Succop, P. Biomechanical Measures of Neuromuscular Control and Valgus Loading of the Knee Predict Anterior Cruciate Ligament Injury Risk in Female Athletes: A Prospective Study. Am. J. Sports Med. 2005, 33, 492-501. [CrossRef]

40. Buckthorpe, M.; Della Villa, F.; Della Villa, S.; Roi, G.S. On-Field Rehabilitation Part 1: 4 Pillars of High-Quality On-Field Rehabilitation Are Restoring Movement Quality, Physical Conditioning, Restoring Sport-Specific Skills, and Progressively Developing Chronic Training Load. J. Orthop. Sports Phys. Ther. 2019, 49, 565-569. [CrossRef]

41. Sigward, S.M.; Powers, C.M. Loading Characteristics of Females Exhibiting Excessive Valgus Moments during Cutting. Clin. Biomech. 2007, 22, 827-833. [CrossRef]

42. Della Villa, F.; Di Paolo, S.; Santagati, D.; Della Croce, E.; Lopomo, N.F.; Grassi, A.; Zaffagnini, S. A 2D Video-Analysis Scoring System of $90^{\circ}$ Change of Direction Technique Identifies Football Players with High Knee Abduction Moment. Knee Surg. Sports Traumatol. Arthrosc. 2021. [CrossRef]

43. Dix, C.; Arundale, A.; Silvers-Granelli, H.; Marmon, A.; Zarzycki, R.; Snyder-Mackler, L. Biomechanical Measures during Two Sport-Specific Tasks Differentiate between Soccer Players Who go on to Anterior Cruciate Ligament Injury and Those who do Not: A Prospective Cohort Analysis. Int. J. Sports Phys. Ther. 2020, 15, 928-935. [CrossRef] [PubMed]

44. Hewett, T.E.; Bates, N.A. Preventive Biomechanics: A Paradigm Shift With a Translational Approach to Injury Prevention. Am. J. Sports Med. 2017, 45, 2654-2664. [CrossRef]

45. Hewett, T.E.; Ford, K.R.; Xu, Y.Y.; Khoury, J.; Myer, G.D. Effectiveness of Neuromuscular Training Based on the Neuromuscular Risk Profile. Am. J. Sports Med. 2017, 45, 2142-2147. [CrossRef]

46. Räisänen, A.M.; Pasanen, K.; Krosshaug, T.; Vasankari, T.; Kannus, P.; Heinonen, A.; Kujala, U.M.; Avela, J.; Perttunen, J.; Parkkari, J. Association between Frontal Plane Knee Control and Lower Extremity Injuries: A Prospective Study on Young Team Sport Athletes. BMJ Open Sport Exerc. Med. 2018, 4, e000311. [CrossRef] [PubMed]

47. Waldén, M.; Krosshaug, T.; Bjørneboe, J.; Andersen, T.E.; Faul, O.; Hägglund, M. Three Distinct Mechanisms Predominate in Non-Contact Anterior Cruciate Ligament Injuries in Male Professional Football Players: A Systematic Video Analysis of 39 Cases. Br. J. Sports Med. 2015, 49, 1452-1460. [CrossRef]

48. Dos'Santos, T.; Bishop, C.; Thomas, C.; Comfort, P.; Jones, P.A. The Effect of Limb Dominance on Change of Direction Biomechanics: A Systematic Review of Its Importance for Injury Risk. Phys. Ther. Sport 2019, 37, 179-189. [CrossRef] [PubMed]

49. Pollard, C.D.; Norcross, M.F.; Johnson, S.T.; Stone, A.E.; Chang, E.; Hoffman, M.A. A Biomechanical Comparison of Dominant and Non-Dominant Limbs during a Side-Step Cutting Task. Sports Biomech. 2020, 19, 271-279. [CrossRef]

50. Mokhtarzadeh, H.; Ewing, K.; Janssen, I.; Yeow, C.-H.; Brown, N.; Lee, P.V.S. The Effect of Leg Dominance and Landing Height on ACL Loading among Female Athletes. J. Biomech. 2017, 60, 181-187. [CrossRef] [PubMed]

51. Romanchuk, N.J.; Del Bel, M.J.; Benoit, D.L. Sex-Specific Landing Biomechanics and Energy Absorption during Unanticipated Single-Leg Drop-Jumps in Adolescents: Implications for Knee Injury Mechanics. J. Biomech. 2020, 113, 110064. [CrossRef]

52. Petrucci, M.; Petrigna, L.; Pomara, F.; Piccione, M.C.; Alesi, M.; Bianco, A. Validation in Young Soccer Players of the Modified Version of the Harre Circuit Test: The Petrucci Ability Test. Montenegrin J. Sports Sci. Med. 2021, 10, 67-71. [CrossRef]

53. Weir, G.; van Emmerik, R.; Jewell, C.; Hamill, J. Coordination and Variability during Anticipated and Unanticipated Sidestepping. Gait Posture 2019, 67, 1-8. [CrossRef] [PubMed] 